\title{
Response to COVID-19 in Ukraine: Legal Pragmatism or Constitutional Outbreak?
}

\section{The Government Set-Up to Fight COVID-19}

On March $11^{\text {th }} 2020$ the newly appointed Ukrainian government that had worked only for one week had to face the global pandemic triggered by COVID-19. On that day the Ukrainian Government introduced a national-wide quarantine which prescribed the closure of all educational institutions and banned mass events. These anticipatory measures were enacted for an initial period of three weeks and subsequently were prolonged and enlarged. On March $17^{\text {th }} 2020$, the Ukrainian Government ordered to halt all public places, except groceries, pharmacies and gas stations; all domestic travels (bus, train, flight) were suspended; international borders - closed for foreigners.

Already on March $25^{\text {th }} 2020$, the Cabinet of Ministers of Ukraine initiated an emergency situation regime upon the request of Arsen Avakov, Minister of Internal Affairs of Ukraine. New in office (since March $4^{\text {th }}$ 2020) Prime Minister of Ukraine Denys Shmygal did his best to calm the Ukrainian nation down and stressed that there were no reasons to enforce a state of emergency under which certain constitutional human rights might be limited. However, Prime Minister did not exclude the possibility of enactment a state of emergency if the situation worsens. By virtue of that decision, the quarantine was prolonged until April $24^{\text {th }} 2020$ (recently the all-nation quarantine has been prolonged till May $\left.11^{\text {th }} 2020\right)$.

On April $4^{\text {th }} 2020$, the Ukrainian Government further toughened restrictive measures by forbidding visits of public places (e.g., parks, playgrounds, etc.), gatherings of more than two people on streets. To add, new regulation prescribed a mandatory 14day quarantine for persons arrived from abroad, the necessity to carry ID documents and wear face masks. The most recent legal steps the Cabinet of Ministers of Ukraine took up on April 8, 2020, wherein the Government specified mandatory observation procedure and clarified the quarantine for the citizens over age of 60 .

Since March 2020 the Verkhovna Rada of Ukraine (Parliament of Ukraine) joined the global fight against COVID-19. It held several plenary sessions and amended certain legislative acts: Law No. 3219 (providing a simplified procedure to purchase services 
and works to fight COVID-19, doubled reward for medical workers, regulated IDPs registration procedure, imposed fines for leaving observation, etc.); Law No. 3220 (on taxation policy during the quarantine; amended law "On the protection of the population from infectious diseases" - clarified the terms of self-isolation, observation, specialized hospitals, processing personal data for health protection purpose does not require consent); Law No. 2538 (specified procedure of purchasing and registration of drugs); Law No. 3268 (on the application of foreign medical protocols to treat COVID-19); Law No. 3276 (extended procedural terms and specified online court sittings, except for criminal cases), and other legal bills. Despite eight Ukrainian MPs have confirmed COVID-19 cases, the work of the Parliament of Ukraine has not been halted.

So far, a state of emergency was introduced in few post-Soviet countries: Kazakhstan (March 16, 2020), Moldova (March 17, 2020), Georgia (March 21, 2020), etc. Ukrainian top officials, with the exception of the former Minister of Health of Ukraine llya Yemets, persuaded that there no pressing need in the adoption of a state of emergency in Ukraine. In the same vein, Ukraine still does not make a derogation from the Convention for the Protection of Human Rights and Fundamental Freedoms, as some other countries did (Latvia; Romania; Moldova; Armenia; Estonia; Georgia; Albania; North Macedonia; Serbia; etc.).

All legal measures limiting human rights in response to COVID-19 adopted by the Cabinet of Ministers of Ukraine are made pursuant with respective clauses of two specific legal acts: the Code of Civil Protection of Ukraine (art. 16) and Law "On the protection of the population from infectious diseases" (art. 3). The said legislation empowers the Cabinet of Ministers of Ukraine as a key body in the protection of the population against infectious diseases with a broad margin of appreciation. However, more importantly, is that the Ukrainian Constitution envisages a restriction on certain rights and freedoms (freedom of movement, art. 33; the right to freedom of thought and speech, and to free expression, art. 34; the right to freedom of beliefs and religion, art. 35; the right to freedom of association, art. 36; the right to assemble peacefully, art. 39; the right to strike, art. 44) if these restrictions are prescribed by law in the interests of protecting the health of the population.

\section{Proponents of the Constitutional Outbreak}

Ukrainian think tanks and NGOs express deep concern on unconstitutionality of limitations of human rights caused by the Government's measures to fight COVID-19. The first concern is that "measures affecting and restricting human rights and freedoms, granted by the Constitution of Ukraine shall be issued only in the event of a state of martial law or of a state of emergency".

The second concern is that according to the Ukrainian Constitution human rights can be limited only under respective provisions of legislative acts, but not under subsidiary legislation, like resolutions of the Cabinet of Ministers - said Andriy Magera, a former member of the Central Election Commission of Ukraine. Observers also noted that certain additional restrictive measures (e.g., temperature screening at the city of Kyiv's entry and exit checkpoints, etc.) taken by local authorities raised a 
lot of questions in terms of legality of said decisions, especially when such measures are even more rigorous than adopted by the Cabinet of Ministers of Ukraine.

Last but not least concern is that some commentators questioned the proportionality of the most radical preventive measures (e.g., a prohibition to walk in parks and few others) and sanctions for their non-compliance. In short, there are two separate points of view: first, the imposed limitations should have been implemented only under a state of emergency clause invoking a special constitutional procedure with rigorous parliamentary supervision; second, modalities and parameters of human rights limitations should have been mandated only under provisions of legislative acts.

\section{Constitutional Outbreak or Legal Pragmatism in Action?}

From the very beginning of the fight against COVID-19 all actions of the Ukrainian Government were made in line, if not duplicating, the same preventive measures introduced earlier or simultaneously in most European countries. Even more, the Ministry of Health of Ukraine pushed changes in treatment COVID-19 cases by using foreign (European, US, Canada, etc.) medical protocols and drugs. Sanctions and fines for violations of anti-epidemiological rules in Ukraine (500-1500 EURO) generally correspond to the penalties enacted in the EU Member States and other European countries (e.g., in Italy penalties may be up to 3000 EURO).

Today, no one can exclude possibility of the introduction of the state of emergency in Ukraine. It opens a door for the expropriation of private property and mobilization of citizens in the interests of national security and health of the population. Needless to say, that such measures will not be welcomed by general public in Ukraine.

The practice of imposition of a state of emergency in European countries is not straightforward and no clear guidelines or recommendations are in place. Thus far, the question clearly falls under a margin of appreciation left to states, especially considering the unprecedented nature of the disease, lack of verified data on how to treat COVID-19 and a non-developed system of healthcare in Ukraine. In opinion of the European Court of Human Rights:

...the notion of necessity implies that the interference must be proportionate to the legitimate aim pursued; in determining whether an interference is "necessary in a democratic society"... a care order should in principle be regarded as a temporary measure, to be discontinued as soon as circumstances permit (ECtHR judgement Kuimov v. Russia, 2009)

In our opinion, current quarantine measures imposed by the Cabinet of Ministers of Ukraine have a temporary character, subjected to permanent scrutiny (the Government of Ukraine amended the initial Resolution five times in two months and provided detailed recommendations), being continuously tailored and individualized to a possible extent, etc. It gives an opportunity to consider that preventive 
measures basically meet the criteria of the Ukrainian Constitution and the European Convention on Human Rights in the present times.

The Code of Civil Protection of Ukraine and Law "On the protection of the population from infectious diseases" directly entailed the Cabinet of Ministers to advance restrictive measures in order to prevent the spread of infectious or other diseases. Every time the taken limitations have to address the threat to public health efficiently and in a cost-effective manner, be limited in time, necessary, and under constant review. The limitations imposed by the Government of Ukraine in response to COVID-19 are consistent with the above-mentioned standards. In so far, we may presume that the Ukrainian authorities act in a manner of legal pragmatism avoiding risky ways to invoke a state of emergency where the Government of Ukraine receives broader powers with the constrained professional expertise and analytical capacities.

\section{Ministry of Internal Affairs - Center of Decision- Making to Fight COVID-19 in Ukraine?}

A surprisingly odd situation happened on March 25th 2020 at the meeting of the Cabinet of Ministers of Ukraine wherein Minister of Internal Affairs Arsen Avakov stepped forward and took in charge of emergency situation regime in Ukraine. It seemed awkward that preventive measures (first of all, measures of medical nature) were advanced not by Minister of Health of Ukraine, but by the Minister of Internal Affairs, Arsen Avakov. Hitherto, he remains one of the principal newsmakers among Ukrainian top officials who is commenting on how Ukraine will react to the COVID-19 crisis. Some legislative steps were taken with objective to broaden the powers of the National Guard of Ukraine (the draft law No. 3105 allowed the National Guard of Ukraine to inspect personal belongings) that is under the direct control of the Minister of Internal Affairs. Apparently Arsen Avakov is the most experienced and longstanding Minister in the Ukrainian Government, but, in our opinion, the scale of the pandemic requires the Ministry of Health of Ukraine to play a key role in coordinating nation-wide actions against COVID-19.

\section{Occupied Territories: As Potential Areas of Uncontrolled Spread of COVID-19 in Ukraine and Beyond}

Ukrainian regulation on crossing administrative border with occupied territories (Donbass area and Crimea) during the quarantine: Since March 2020, the Cabinet of Ministers of Ukraine allowed crossing the contact line only if such a person has residence registration (on the territory uncontrolled by the Ukrainian Government). The State Border Guard Service may allow crossing the contact line in exceptional cases for other citizens (in case of family separation, medical treatment, etc.). There were few reported cases when the occupying administration in non-governmentcontrolled areas prohibited to enter for persons who had residence registration 
or travel for an urgent purpose. It followed that Ukraine, Moldova, and Georgia applied a common humanitarian policy to address the spread of COVID-19 on the uncontrolled areas. All mentioned countries allowed citizens who need medical treatment to have access to healthcare institutions on the territory controlled by the government. In the meantime, experts observe that continuing disrespect to $\mathrm{IHL}$ obligations by the Russian Federation may severely jeopardize the efforts to prevent the spread of COVID-19 non-government-controlled areas in Crimea and Eastern Ukraine.

\section{Protection of Personal Data: How to Control Observation and Respect Private Life?}

On April $16^{\text {th }} 2020$ President Vladimyr Zelensky signed the draft law that permits authorized agencies to process personal data without the consent of the person for preventing the spread of COVID-19. The collected data may include information about health, place of hospitalization or observation, name, date of birth, residence, and work. The collection of personal data under that special procedure is limited by the period of the quarantine and is to be varnished at the end of the quarantine. That change may deem necessary, albeit tends to be superfluous. In many regards, the procedure of consent to process personal data is rather formal and, usually, accepted nearly always by a person.

\section{Concluding Remarks}

So far, legal measures adopted by Ukrainian authorities seemed as an attempt to be pragmatic in today's fragile political and economic environment and circumstances. There is no sign that Ukrainian authorities intentionally took steps contrary to the very idea of human rights or acting against basic constitutional guarantees as enshrined in the Constitution of Ukraine and fundamental principles of human rights. The imposed measures, however, should be under permanent review by national and international whistleblowers and narrowed as much as possible if the pandemic situation allows.

(cc) $\mathrm{BY}-\mathrm{NC}-\mathrm{ND}$ 